\title{
Usos y efectos de los préstamos en las microempresas desde una perspectiva de generación de valor
}

\section{Uses and effects of loans in micro-enterprises from a value- generation perspective}

Janeth Chunga Hernández*

Hugo Bécquer Paz Quintero**

\section{Resumen}

Este artículo busca establecer los efectos que los préstamos, utlizados por los microempresarios de la comuna 18 de Cali, tienen sobre los negocios en relación al concepto de generación de valor. Para el logro de lo anterior, se construyó un instrumento de encuesta en escala Likert que permitió identificar los usos que los microempresarios dan a los recursos que obtienen a través de préstamos, así como también los efectos que ellos reconocen sobre las unidades productivas. Entre los resultados encontrados se evidenció que el uso más frecuente que le dan a estos recursos es para la compra de mercancía y la ampliación de los negocios; y, en relación con los efectos, se encuentran principalmente asociados a un incremento en inventarios y ventas. También se pudo establecer una gran debilidad en relación a conocimientos contables y financieros, lo cual representa una barrera para orientar sus decisiones de consecución de recursos a través de préstamos con la perspectiva de generación de valor.

Palabras claves: préstamos, generación de valor, microempresarios, conocimiento financiero, sostenibilidad, desarrollo, incremento del patrimonio.

\section{Abstract}

This article seeks to establish the effects that the loans, used by the micro entrepreneurs of the commune 18 of Cali, have on the business in relation to the concept of value generation. To achieve this, a survey instrument was built on a Likert scale that allowed the identification of the uses that micro entrepreneurs make over the resources obtained through loans, as well as the effects they recognize on productive units. The results showed that the most frequent use of these resources is the purchase of merchandise and the expansion of business. Furthermore, concerning the impacts, they are mainly associated with the increase of inventories and sales. It was detected a great weakness in relation to accounting and financial knowledge, representing a barrier in their decisions to obtain resources through loans with the perspective of value generation.

Keywords: loan, value generation, micro entrepreneurs, financial knowledge, sustainability, development, patrimony growth.

\footnotetext{
* Magister en Administración con énfasis en Finanzas Corporativas de la Universidad Icesi. Administradora de Empresas de la Universidad del Valle. Docente Investigadora de la Fundación Universitaria Católica Lumen Gentium. jchunga@unicatolica.edu.co

**Doctor en Gestión Tecnológica e Innovación de la Universidad Autónoma de Querétaro, Qro. México. Magister en Ingeniería de Sistemas de la Universidad del Valle. hbecquer@gmail.com
} 


\section{Introducción}

Los préstamos constituyen una de las formas en que pueden financiarse tanto los individuos como las empresas para la realización de proyectos, los cuales tienen un costo representado en la tasa de interés asociada a ellos. Por la diversidad de opciones que existen en el mercado es importante tener un conocimiento apropiado de las características de cada tipo de préstamo, lo que permitiría utilizarlos de una manera informada, buscando siempre que el beneficio que generen sea superior a los costos de utilizarlos, es decir, apegados al concepto de generación de valor.

Teniendo en cuenta que el sector microempresarial representa una comunidad en condiciones de vulnerabilidad que está expuesta a los retos que le presenta un entorno globalizado, donde tiene que competir con producción interna y externa, lo cual lo pone en riesgo de, a pesar de su sostenibilidad, no tener las posibilidades de crecimiento y desarrollo y de no generar las condiciones para una adecuada empleabilidad (Chunga, González y Márquez, 2017, p. 29).

La investigación buscó identificar el uso que los microempresarios dan a los recursos conseguidos a través de préstamos y cuál es la percepción que ellos tienen de los efectos que se les presenta sobre sus negocios, para así establecer si estas decisiones de inversión y financiación están basadas en los conceptos de generación de valor. Para el logro de lo anterior se construyó una encuesta, con preguntas tipo Likert, la cual se aplicó a una muestra representativa de los microempresarios de la comuna 18 en julio de 2016.

La población para la aplicación del instrumento fue seleccionada por estar en el área de influencia de la sede de Meléndez de la Fundación Universitaria Católica Lumen Géntium, entidad financiadora de la investigación que dio origen a este artículo, como mecanismo para identificar necesidades de esta población con miras a ofrecer alternativas de solución desde la academia en el marco de la responsabilidad social universitaria, para las necesidades que los aquejan en particular las originadas por el financiamiento que utilizan en sus negocios.

\section{Perspectiva teórica}

\author{
Jiménez, Caballero y de la Torre (2008), \\ establecen que:
}

(...) el enfoque moderno de las finanzas relaciona problemáticas que tienen que ver con la dimensión de la empresa y su ritmo de crecimiento, el tipo de activos a adquirir y la composición del pasivo. En lo referente al corto plazo se abordan temas relacionados con los niveles óptimos de tesorería, de fondo de maniobra y el tipo de inversiones que deben realizarse, entre otros. Adicionalmente, este enfoque se nutre de dos campos, uno abarca los estudios relativos a las decisiones de inversión y financiación empresarial y el otro gira en torno al comportamiento de los individuos y empresas en relación con su actividad económico financiera, es decir, que el enfoque moderno involucra en el análisis además de las empresas la actividad financiera de los individuos como personas naturales y sus actividades relacionadas con la consecución de recursos y las diferentes aplicaciones que hacen de los mismos (p. 29).

Adicionalmente, según García (2009), el objetivo básico financiero de la empresa es el "incremento del patrimonio de los accionistas en armonía con los objetivos asociados con clientes, trabajadores y demás grupos de interés" (p. 5). Esto se encuentra en concordancia con Gitman (2007), quien sostiene que "incrementar al máximo la riqueza de los accionistas es la meta principal, muchas empresas amplían su enfoque para incluir los intereses de grupos de empleados, clientes, proveedores, acreedores, propietarios y otros que tengan una relación directa con la organización" (p. 13-14).

Es muy importante dimensionar el alcance del objetivo básico financiero, dado que si este es limitado al incremento del patrimonio de los inversionistas, únicamente se le estaría apuntando al incremento de las utilidades desde una perspectiva del corto plazo, lo cual podría afectar la organización en su desempeño y sostenibilidad; mientras que si este objetivo se asume teniendo en cuenta todos los grupos de interés, se podría incurrir en principio en sacrificio de utilidades para los inversionistas, buscando el fortalecimiento de la empresa con nuevos proyectos como nuevas líneas de 
productos o servicios, nuevas sedes con miras a ampliación de mercados, lo que impactaría el área productiva y permitiría mayor generación de empleo, posibilidad de invertir en el personal para que esté más motivado y por ende más productivo, traduciendose al final en mayores utilidades para los inversionistas así como también en beneficios para todas las partes relacionadas.

$\mathrm{Al}$ asumir el objetivo básico financiero en un horizonte de largo plazo, vale aclarar que la administración financiera tendrá que realizar una serie de funciones en su diario vivir, tales como"consecución de fondos, administración de capital de trabajo, diagnóstico de la situación financiera, planeación, control financiero y la evaluación de proyectos de inversión, las cuáles ayudarán en la consecución del objetivo financiero" (Carrillo de Rojas, 2006, p. 3).

En relación con lo expresado antes, el objetivo financiero debe perseguir el bienestar de los accionistas y este se puede conseguir a través de la maximización del valor de mercado de la empresa (Jiménez, Pérez y de la Torre, 2008), lo cual se logra con el compromiso de todos los grupos de interés de la compañía; teniendo en cuenta que según Blank y Tarquin (2000), las decisiones de inversión y financiación que se toman a diario cambian el futuro de las empresas y las personas de una manera positiva o negativa; además sostiene que los recursos económicos siempre serán una variable limitante en esta toma de decisiones y es por esto que las decisiones de inversión y financiación buscan la generación de valor en las organizaciones, es decir, el incremento del patrimonio y esto se logra según Carrillo (2006) cuando una empresa:

(...) genera mayores rendimientos que el costo del capital utilizado en su operación, teniendo en cuenta que el capital está constituido por los aportes de los inversionistas y la deuda, donde el costo de los aportes se conoce como el costo de oportunidad el cual representa el pago que espera el accionista si invirtiera su dinero en otro negocio de igual riesgo y el costo de la deuda está representado en los intereses que se pagan por ella ajustados por las deducciones de impuestos que correspondan (p. 469).

En la misma línea, Valencia (2011) expresa que en todas las actividades que desarrollan las empresas se generan costos y para que ésta sea viable se deben lograr ingresos que cubran todos éstos incluidos los costos del financiamiento y solo a partir de allí se empieza a generar valor para la empresa, pues de lo contrario, se estaría in- curriendo en déficit o destrucción de valor, lo que traería como consecuencia el uso de recursos de otras fuentes para cubrir lo perdido.

El modelo del Valor Económico Agregado (EVA) plantea que toda empresa tiene diferentes objetivos de carácter económico-financiero, y entre los más importantes se encuentran:

a) aumentar el valor de la empresa y por tanto la riqueza de los propietarios, lo cual está relacionado con la consecución de la mayor utilidad con aportes mínimos de los inversionistas; b) trabajar con el mínimo riesgo, lo que requiere una proporción equilibrada entre el endeudamiento e inversión, equilibrio entre obligaciones financieras de corto y de largo plazo y cobertura de diferentes tipos de riesgo, tasas de cambio, intereses del crédito y de los valores bursátiles y c) disponer de niveles óptimos de liquidez, esto depende del financiamiento adecuado de los activos corrientes y el equilibrio entre recaudos y pagos (Acuña, 2001, párr. 8).

El objetivo básico financiero plantea a los gerentes de las empresas, la necesidad de la creación de valor a partir de las decisiones de inversión y financiación que se toman al interior de estas, lo que ha dado como resultado la tendencia gerencial denominada Gerencia del Valor, la cual se entiende como una nueva cultura empresarial que permite que todos los funcionarios que participan en la toma de decisiones midan el alcance de estas en términos del posible valor que puedan crear o destruir. Lo anterior requiere:

(...) el trascender de los indicadores tradicionales como el crecimiento en ventas, utilidades, márgenes de utilidad como parámetros del desempeño organizacional, para relacionarlos con la generación de valor y que sean utilizados como medios para establecer comunicación entre los diferentes niveles de la empresa y el alineamiento de los objetivos (García, 2009, p. 156).

Lo anteriormente expuesto resalta la importancia de la información financiera como medio de apoyo para la toma de decisiones de los negocios, pues entre mejor sea la calidad de la información, mayor probabilidad de éxito en las decisiones que se tomen. Para lograr dicha calidad es importante contar con datos que satisfagan las necesidades de los diferentes usuarios, tal es el caso de los informes resultantes del sistema contable los cuáles proveen "información relacionada con la liquidez, la rentabilidad, el crecimiento, el apalancamiento y la productividad" (Ramírez, 2008, p. 13); subsistemas 
que representan parámetros relevantes para el sostenimiento y desarrollo empresarial, a través de la generación de valor.

En concordancia con lo anterior, Sinisterra y Polanco (2007, p. 10), expresan que toda persona, independientemente de a qué se dedique, debe tomar decisiones enmarcadas en lo económico, lo social y lo personal y que la información contable debe contribuir a la toma objetiva de tales decisiones, ya que la contabilidad como fuente de información de la actividad económica tiene por objetivo producir periódicamente información expresada en términos monetarios, en la cual se refleja la actividad económica realizada, ya sea por personas naturales, empresas y entidades sin ánimo de lucro. Lo anterior refleja la necesidad de algún grado de conocimiento contable para un desempeño eficiente en la sociedad.

\section{Metodología y materiales}

La investigación desarrollada que da origen al presente artículo, es de tipo cuantitativo, con un enfoque descriptivo, ya que de acuerdo con Hernández (2006), pretende presentar"la realidad que viven los microempresarios, con relación a los préstamos que realizan y los efectos que éstos tienen en sus unidades productivas, de una manera objetiva" (p. 43).
Se diseñó un instrumento con dos partes, la primera con 10 preguntas tipo selección múltiple, cada una con un número de opciones diferentes para consultar información general del microempresario; en la segunda parte se consultaron aspectos relacionados con la aplicación que dieron a los recursos obtenidos a través de los préstamos y la percepción que los microempresarios tuvieron en relación con los efectos que el uso de estos recursos tuvo en sus negocios.

\section{Cálculo de la muestra}

De acuerdo con el reporte de empresas matriculadas y renovadas en la Cámara de Comercio de Cali al 2.014, existe una población de 694 microempresas en los barrios Caldas, Buenos Aires, Meléndez y Nápoles, de la comuna 18, en todos los principales sectores económicos existentes de los que forman parte los negocios de la zona, cuya distribución se muestra en la Tabla 1.

De acuerdo con la población identificada, descrita en la Tabla 1, se procedió a determinar la muestra mediante la fórmula para el cálculo de muestras estadísticas de poblaciones grandes, ecuaciones (1) y (2), cuyos parámetros se describen en la Tabla 2. De acuerdo con estos cálculos, se obtuvo una muestra (n) de 76 microempresarios a encuestar.

Tabla 1.

Resumen del número de microempresas matriculadas en la Comuna 18 de Cali

\begin{tabular}{|c|c|c|c|c|c|}
\hline Nombre de sector & Barrio Caldas & Buenos Aires & Meléndez & Nápoles & Total \\
\hline Actividades artísticas, de entretenimiento y recreación & 2 & 1 & 13 & 5 & 21 \\
\hline Actividades de atención de la salud humana y de asistencia social & 4 & 1 & 6 & 2 & 13 \\
\hline Alojamiento y servicios de comida & 14 & 8 & 22 & 11 & 55 \\
\hline $\begin{array}{l}\text { Comercio al por mayor y al por menor; reparación de vehículos } \\
\text { automotores y motocicletas }\end{array}$ & 53 & 68 & 137 & 53 & 311 \\
\hline Construcción & 3 & 7 & 30 & 22 & 62 \\
\hline Educación & 1 & 3 & 5 & 3 & 12 \\
\hline Industrias manufactureras & 26 & 21 & 37 & 26 & 110 \\
\hline Información y comunicaciones & 1 & 3 & 17 & 8 & 29 \\
\hline Otras actividades de servicios & 9 & 13 & 31 & 6 & 59 \\
\hline Transporte y almacenamiento & 2 & 4 & 9 & 7 & 22 \\
\hline TOTAL & 115 & 129 & 307 & 143 & 694 \\
\hline
\end{tabular}




$$
\begin{aligned}
& n=\frac{Z^{2 * N * p * q}}{E^{2}(N-1)+Z^{2 *} p^{*} q} \quad(1) \\
& n=\frac{1.96^{2 * 69} 64^{*} 0.80^{*} 0.20}{0.085^{2}(694-1)+1.96^{2 *} 0.80 * 0.20} \cong 76
\end{aligned}
$$

Tabla 2.

Parámetros para el cálculo de la muestra

\begin{tabular}{lll}
\hline Parámetro & Valor & \multicolumn{1}{c}{ Descripción } \\
\hline $\mathrm{N}=$ & 694 & Tamaño de la población \\
$\mathrm{Z}=$ & 1,96 & Nivel de confianza del $95 \%$ \\
$\mathrm{p}=$ & 0,80 & Probabilidad de ocurrencia del parámetro a evaluar \\
$\mathrm{q}=$ & 0,20 & Probabilidad de no ocurrencia del parámetro $(1-\mathrm{p})$ \\
$\mathrm{E}=$ & 0,085 & Error esperado \\
& & \\
& $\mathrm{n}=76$ & Tamaño de la muestra \\
\hline
\end{tabular}

Fuente: elaboración propia.

\section{Estratificación de las microempresas de la} Comuna 18

Basados en la distribución de la Tabla 1, se calcularon las proporciones de microempresas para cada sector de cada barrio, lo que se muestra en la Tabla 3. Lo anterior se hizo dividiendo cada valor de la intersección entre sector y barrio sobre el gran total de microempresas (694). Este resultado se multiplicó por cien, para expresarlo en porcentaje, redondeado a una décima.

Tabla 3.

\begin{tabular}{|c|c|c|c|c|c|}
\hline Nombre de sector & Barrio Caldas & Buenos Aires & Meléndez & Nápoles & Total \\
\hline Actividades artísticas, de entretenimiento y recreación & 0,3 & 0,1 & 1,9 & 0,7 & 3,0 \\
\hline $\begin{array}{l}\text { Actividades de atención de la salud humana y de asistencia } \\
\text { social }\end{array}$ & 0,6 & 0,1 & 0,9 & 0,3 & 1,9 \\
\hline Alojamiento y servicios de comida & 2,0 & 1,2 & 3,2 & 1,6 & 8,0 \\
\hline $\begin{array}{l}\text { Comercio al por mayor y al por menor; reparación de } \\
\text { vehículos automotores y motocicletas }\end{array}$ & 7,6 & 9,8 & 19,7 & 7,6 & 44,7 \\
\hline Construcción & 0,4 & 1,0 & 4,3 & 3,2 & 8,9 \\
\hline Educación & 0,1 & 0,4 & 0,7 & 0,4 & 1,6 \\
\hline Industrias manufactureras & 3,7 & 3,0 & 5,3 & 3,7 & 15,7 \\
\hline Información y comunicaciones & 0,1 & 0,4 & 2,4 & 1,2 & 4,1 \\
\hline Otras actividades de servicios & 1,3 & 1,9 & 4,5 & 0,9 & 8,6 \\
\hline Transporte y almacenamiento & 0,3 & 0,6 & 1,3 & 1,0 & 3,2 \\
\hline TOTAL & 16,4 & 18,5 & 44,2 & 20,6 & 99,7 \\
\hline
\end{tabular}

Porcentajes de microempresas por barrio y sector económico. Comuna 18 de Cali

Fuente: Adaptado de Cámara de Comercio de Cali (2014). 


\section{Muestreo estratificado acorde con la muestra seleccionada}

Se realizó la estratificación teniendo en cuenta las actividades económicas y los barrios de la comuna 18. Con las proporciones de la Tabla 3 y el valor de la muestra hallada (76 microempresas), se procedió a multiplicar este valor por cada uno de los porcentajes calculados en la tabla en mención. Lo anterior arrojó las cantidades por sectores económicos de cada barrio, que corresponde al método de estratificación aplicado. El resultado se muestra en la Tabla 4.

Tabla 4.

Resultados del muestreo estratificado según la muestra calculada

\begin{tabular}{|c|c|c|c|c|c|}
\hline Nombre de sector & Barrio Caldas & Buenos Aires & Meléndez & Nápoles & Total \\
\hline $\begin{array}{l}\text { Actividades artísticas, de entretenimiento y } \\
\text { recreación }\end{array}$ & - & - & 1 & 1 & 2 \\
\hline $\begin{array}{l}\text { Actividades de atención de la salud humana y de } \\
\text { asistencia social }\end{array}$ & - & - & 1 & - & 1 \\
\hline Alojamiento y servicios de comida & 2 & 1 & 2 & 1 & 6 \\
\hline $\begin{array}{l}\text { Comercio al por mayor y al por menor; reparación } \\
\text { de vehículos automotores y motocicletas }\end{array}$ & 6 & 7 & 15 & 6 & 34 \\
\hline Construcción & - & 1 & 3 & 2 & 6 \\
\hline Educación & - & - & 1 & - & 1 \\
\hline Industrias manufactureras & 3 & 2 & 4 & 3 & 12 \\
\hline Información y comunicaciones & - & - & 2 & 1 & 3 \\
\hline Otras actividades de servicios & 1 & 1 & 3 & 1 & 6 \\
\hline Transporte y almacenamiento & - & - & 1 & 1 & 2 \\
\hline TOTAL & 12 & 12 & 33 & 16 & 73 \\
\hline
\end{tabular}

Fuente: Elaboración propia

El resultado del muestreo estratificado arrojó unos valores redondeados al entero más cercano. Los lugares en guion significan que dio un valor menor a 0.5 , y al sumar totales dio la cantidad de 73, la cual se disminuyó por razón del redondeo practicado, lo que hace que para completar la muestra se eligieron aleatoriamente las tres microempresas faltantes.

Se procedió entonces a realizar la prueba piloto a nueve microempresarios de la zona seleccionada en la comuna 18. Después de realizada, se hicieron algunos ajustes, antes de continuar con la aplicación de las encuestas restantes en el mes de Julio de 2016.

\section{Resultados}

A continuación, se describen los resultados obtenidos en la aplicación de la encuesta, los cuales muestran algunas características de los microempresarios y sus negocios, así como el uso que dan a los préstamos que realizan y los efectos que éstos tienen sobre sus microempresas.

\section{Características de los microempresarios y sus negocios}

Edad de la persona que responde. En la Figura 1 se puede observar que el $62 \%$ de las personas que 
respondieron la encuesta tiene más de 41 años y el $38 \%$ restante tiene menos de 30 años.

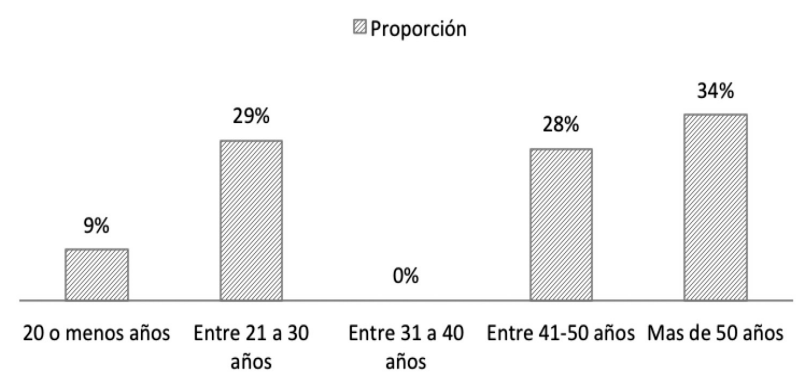

figura1. Rango de edades de las personas encuestadas Fuente: Elaboración propia.

Máximo nivel de formación de quienes respondieron la encuesta. En la Figura 2 se presenta que el nivel máximo de estudios predominante en las personas encuestadas es bachillerato, con un $34 \%$; le siguen técnicos, con un $25 \%$. El nivel de primaria tiene una representación del 16\%, tecnólogo y profesional el 12 \% cada uno, y estudios a nivel de maestría, un $1 \%$.

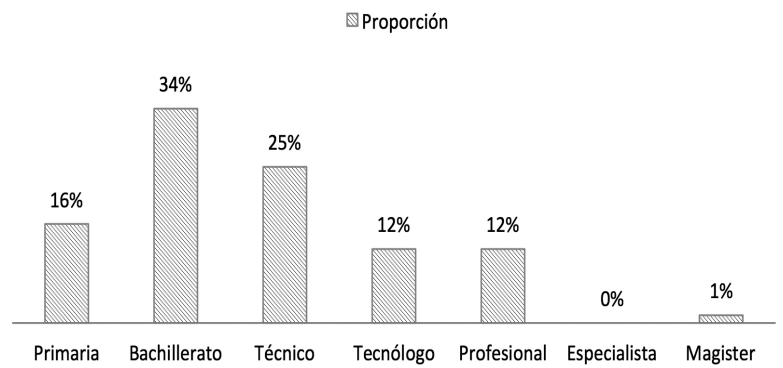

figura 2. Proporción niveles de formación personas encuestadas Fuente: Elaboración propia.

Fecha de creación del negocio. La Figura 3 evidencia que el $9 \%$ de los negocios pertenecientes a la muestra tiene entre 32 y 37 años de creación; el $5 \%$ entre 27 y 31 años; el $1 \%$ entre 22 y 26 años, el $17 \%$ entre 17 y 21 años; el $21 \%$ entre 12 y 16 años; el $22 \%$ entre 7 y 11 años y el $25 \%$ entre 2 y 6 años.

『roporción

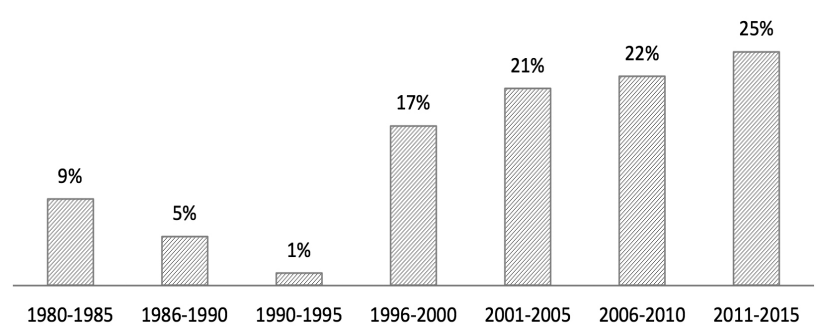

Número de personas que trabajan en el negocio. En la Figura 4 se evidencia que el $72 \%$ de los negocios pertenecientes a la muestra tiene entre tres o menos trabajadores; el $21 \%$ tiene entre cuatro y seis empleados y el $7 \%$ emplea entre siete y diez personas.

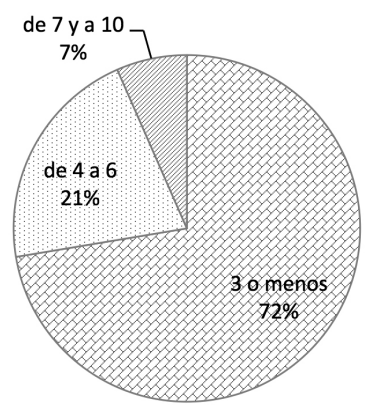

Figura 4. Número de empleados empresas encuestadas Fuente: Elaboración propia.

\section{Uso del dinero recibido en préstamo}

Los resultados de esta variable permitieron evidenciar el uso que los microempresarios le han dado a los recursos conseguidos en préstamo y si ese uso está apegado al concepto de generación de valor, así como establecer si ellos reconocen el impacto que estos recursos tienen en el negocio. En la Figura 5 se puede observar que el $97 \%$ de la muestra encuestada contestó nunca o muy pocas veces haber utilizado el dinero recibido en préstamo para el pago de nómina; el 96 \% se expresó de igual forma en relación con el pago de impuestos; el 90 \% respondió lo mismo sobre el aprovechamiento de descuento; el $75 \%$ manifiesta que el uso del dinero recibido en préstamo nunca o muy pocas veces lo ha utilizado para reparaciones locativas; el $54 \%$ se expresa de igual forma en relación con la ampliación del negocio y el $93 \%$ afirma que nunca o muy pocas veces ha utilizado estos recursos para el pago de facturas vencidas.

El porcentaje restante expresó que ha utilizado el dinero recibido en préstamos algunas veces, con alguna frecuencia o frecuentemente en el pago de nómina (3\%); impuestos (4\%); reparaciones locativas (25\%); aprovechamiento de descuentos (10 \%); ampliación del negocio (46 \%) y pago de facturas vencidas $(7 \%)$.

Figura 3. Rango de fechas creación de negocios encuestados Fuente: Elaboración propia. 


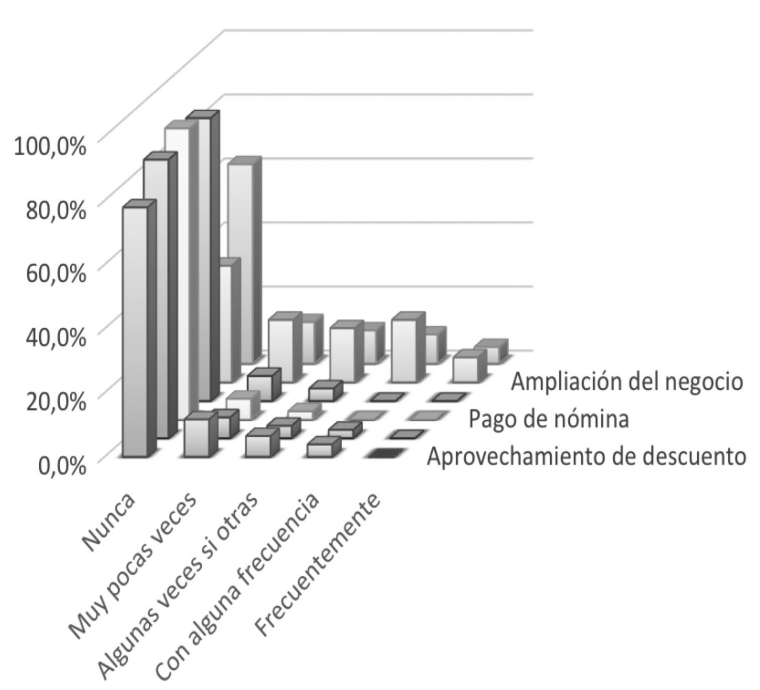

Figura 5. Uso del dinero recibido en préstamos Fuente: Elaboración propia.

En la Figura 6 se puede observar que el $97 \%$ de los encuestados respondió que nunca o muy pocas veces ha utilizado el dinero recibido en préstamo para el pago de tarjetas de crédito; el $96 \%$ se expresó de igual forma con respecto a la compra de cartera; el $80 \%$ nunca o muy pocas veces ha utilizado los recursos provenientes de los préstamos en requerimientos personales; el 59\% contestó que nunca o muy pocas veces ha utilizado estos recursos para compra de mercancía. El porcentaje restante en cada uno de los ítems manifiesta que algunas veces, con alguna frecuencia o frecuentemente ha utilizado los recursos provenientes de los préstamos para requerimientos personales, compra de mercancía, pago de tarjeta de crédito o compra de cartera.

Por otro lado, el $100 \%$ de los encuestados expresa que nunca o muy pocas veces ha utilizado dinero proveniente de préstamos para el pago de servicios públicos.

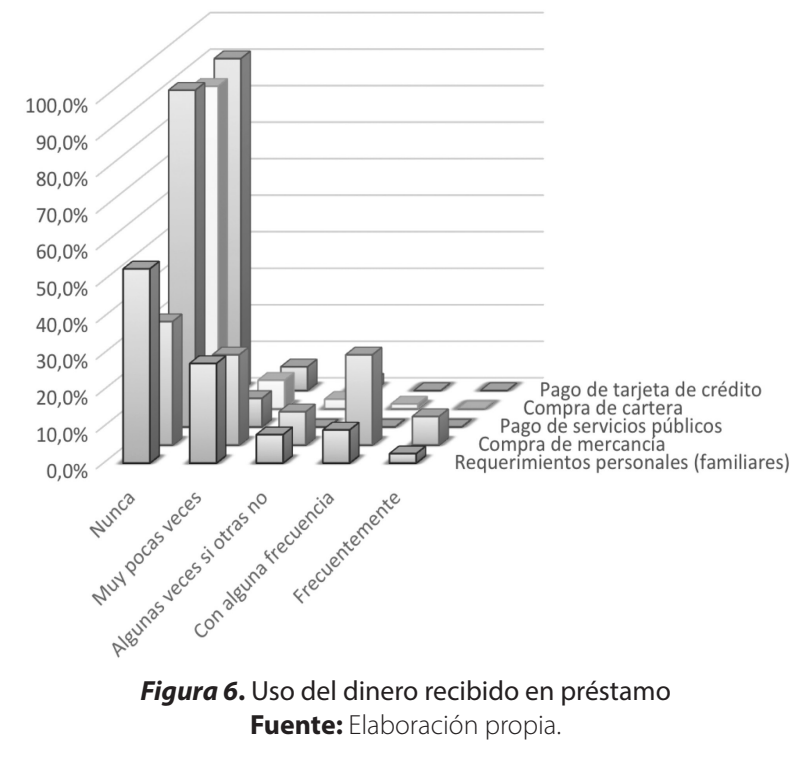

Efectos de los préstamos adquiridos

La Figura 7 permite evidenciar los efectos que los microempresarios reconocen por el uso de los préstamos en sus negocios. El 50 \% expresó que las ventas aumentaron o aumentaron bastante por el uso de préstamos, el $38 \%$ no reconoció ningún efecto de los préstamos sobre las ventas, y el 9 \% contestó que los préstamos hicieron que las ventas decrecieran.

El $53 \%$ de la muestra encuestada contestó que los préstamos realizados no tienen efecto alguno sobre las deudas, el $25 \%$ respondió que estas incrementaron en razón a los préstamos solicitados y el 19 \% expresó que las deudas decrecieron como efecto de los préstamos recibidos.

Con respecto al flujo de caja disponible, el 43 \% respondió que se incrementó, el 42 \% expresó que los préstamos no tuvieron efecto sobre la disponibilidad de caja, y el 12 \% contestó que el efectivo decreció.

En lo relacionado con las utilidades, el $49 \%$ de la muestra encuestada no reconoció ningún efecto de los préstamos sobre las utilidades, el 36 \% manifestó que estas aumentaron y el $12 \%$ expresó que disminuyeron. Acerca de los inventarios, el $50 \%$ de la muestra encuestada contestó que estos incrementaron por causa de los préstamos recibidos, el $42 \%$ no reconoció ningún efecto de los préstamos sobre esta variable y el $6 \%$ respondió que los inventarios decrecieron en razón a los préstamos recibidos. Frente a los gastos, el 53 \% de la muestra encuestada no 
reconoció relación alguna con los préstamos recibidos, el 31 \% respondió que los gastos incrementaron por efecto de esta variable y el $13 \%$ expresó que los gastos se redujeron.

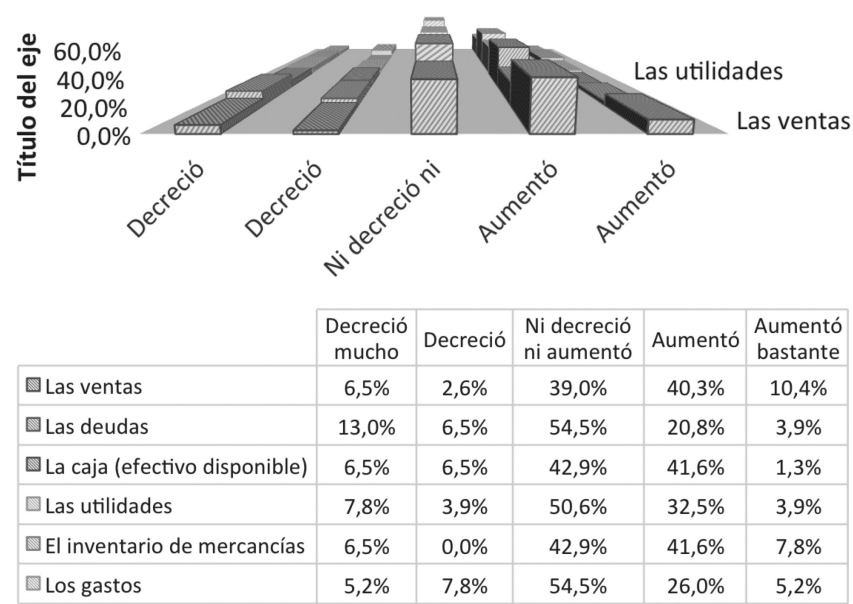

Figura 7. Efectos de los préstamos adquiridos Fuente: elaboración propia.

\section{Discusión}

La mayoría de los propietarios y administradores de las microempresas de la comuna 18 tienen más de 41 años, su nivel predominante de estudios es el bachillerato y el técnico; la antigüedad de la mayoría de los negocios es mayor o igual a 12 años y emplean de uno a tres trabajadores.

Los datos presentados muestran una gran debilidad de los negocios en relación con el nivel de formación de sus propietarios y administradores, pues a pesar de que son administrados por personas en edad madura, se puede inferir que pesa más la poca formación que tienen, dado que la mayoría de los negocios, a pesar de tener más de una década de existencia, no cuentan con una estructura laboral de más de tres empleados. Esta situación puede estar relacionada con el hecho de que los propietarios y administradores de estos negocios no han contado con las herramientas necesarias para enmarcar las decisiones que toman al interior de los negocios desde una perspectiva de generación de valor que les permita el crecimiento y desarrollo de sus unidades productivas, pues los datos solo evidencian el logro de la sostenibilidad a través del tiempo. No obstante, un porcentaje importante $(47 \%)$ está representado en negocios que tienen una antigüedad inferior a 12 años lo que permite catalogarlos como negocios jóvenes que corren mayor riesgo de fracaso, ya que de acuerdo a Confecámaras (2014), el 86 \% de las empresas en Colombia son de edad joven y mediana y el promedio de edad que vive una empresa en el país es de 12 años.

Lo anterior sugiere la necesidad de realizar acciones que apoyen la gestión en las microempresas para el logro de su perdurabilidad, por ejemplo, promover al interior de estas la cultura de la Gerencia delValor tal y como lo plantea García (2009), es decir, que las decisiones que se tomen estén en función de la riqueza que puedan crear o destruir.

En cuanto al uso que los microempresarios han dado a los recursos obtenidos a través de préstamos, los más representativos son la compra de mercancía y la ampliación del negocio, conceptos que podrían ajustarse a la perspectiva de Generación deValor, pues la inversión en inventarios permite desarrollar el objeto social y la ampliación del negocio apunta a mejorar la capacidad instalada con miras a la mejora de la productividad. Pero la creación de valor solo se da en tanto que la inversión en inventarios y ampliación de la capacidad instalada genere rendimientos por encima del costo del crédito. Sin embargo, es de resaltar que esta práctica en cuanto al uso del dinero de los préstamos por parte de los microempresarios no constituye la mayoría de ellos.

Adicionalmente, los resultados reflejan que si bien los microempresarios no utilizan los recursos de los préstamos en conceptos tales como pago de nómina, impuestos, requerimientos personales, servicios públicos, tarjetas de crédito, entre otros, que los pondrían en riesgo frente a la destrucción de valor, también dejan de utilizarlos en aprovechamiento de descuentos y compra de cartera, conceptos que pueden constituir oportunidad para generar riqueza al interior de sus negocios, y por ende, incremento del patrimonio.

Por otro lado, los microempresarios en su mayoría reconocen que los préstamos utilizados ayudaron a incrementar las ventas y los inventarios en su negocio, sin embargo, la mayoría no reconoce efectos de los préstamos sobre las utilidades, las deudas y los gastos, y un porcentaje importante no reconoce efectos sobre las ventas, la caja y los inventarios. 
Los datos anteriores permiten inferir que los microempresarios no tienen una cultura de la Gerencia del Valor en razón a que las decisiones en relación con los préstamos adquiridos y los usos que hacen de los mismos no evidencian la intención de la búsqueda de un incremento del patrimonio, es decir, la administración de los negocios en este tipo de decisiones, según García (2009),"no mide el posible valor que puedan crear o destruir" (p. 27), ya que, si bien reconocen el efecto que esta decisión de financiación tiene sobre las ventas (aumento), no establecen la relación lógica del incremento de utilidades seguido de un incremento en ventas.

Asimismo, no se relaciona esta fuente de consecución de recursos con aspectos a los que hace referencia el modelo de valor económico agregado, descrito por Acuña (2001), tales como lograr las mayores utilidades con aportes mínimos de los socios, manejo de la liquidez a través de un adecuado financiamiento de los activos corrientes y manejo de variables de riesgo como una adecuada proporción entre obligaciones financieras de corto y de largo plazo, entre otros elementos. Esto se presenta de acuerdo con las respuestas de los microempresarios encuestados, a causa de la falta de reconocimiento del impacto que tienen los préstamos sobre la disponibilidad de efectivo, las posibilidades de generar mayores utilidades, relacionando los beneficios que se puedan obtener con los gastos financieros en los que se incurre, pues no dimensionan el incremento de los gastos al adquirir préstamos. Igualmente, al no existir claridad sobre el impacto en el endeudamiento, es difícil controlar la proporcionalidad que debe existir entre los préstamos de corto y largo plazo, y la relación que debe existir con la inversión total del negocio.

Lo expresado anteriormente refleja un gran vacío en el conocimiento de información contable como apoyo para la toma de decisiones financieras por parte de los microempresarios, lo cual representa un obstáculo para la correcta administración de sus negocios. Como lo afirma Sinisterra y Polanco (2007), el conocimiento contable es altamente importante para el empresariado, ya que este sistema provee la información de los hechos económicos de los negocios. Frente a esto, que los microempresarios desconozcan y no utilicen este clase de información para la toma de decisiones, los expone a que sus decisiones financieras se construyan desde la desinformación, situación que van en contravía de la perspectiva de Generación deValor en las empresas y del incremento de su patrimonio como mecanismo para que los negocios crezcan, se desarrollen y perduren a través del tiempo.

Asimismo, teniendo en cuenta que "las microempresas presentan un alto grado de informalidad en su manera de funcionar internamente" (Márquez y Chunga, 2016 p. 157), se genera el interrogante sobre si el vacío que tienen los microempresarios de temas contables y financieros están relacionado con sus niveles de formación, que en su mayoría no superan los niveles de bachillerato y técnico, o que estas empresas no producen información contable y financiera que les permita apoyar la toma de decisiones de inversión y financiación con miras a solidificar sus negocios a futuro.

\section{Conclusión}

Después de analizar los resultados de la investigación, se puede concluir que los microempresarios, si bien financian sus negocios a través de préstamos, no sustentan sus decisiones bajo los conceptos de Generación de Valor. Esta situación se evidencia en relación a los limitados usos que los microempresarios dan a estos recursos, desaprovechándolos para otras alternativas que ofrece el mercado y que les pueden representar oportunidades de mejora.

Lo anterior se puede explicar por los bajos niveles educativos que se observan en sus propietarios y administradores, aunado al poco conocimiento contable y financiero que se evidencia en ellos, lo cual los convierte en una población vulnerable en cuanto a su incapacidad para reconocer oportunidades y riesgos en la toma de decisiones informadas, que ayuden al desarrollo y sostenibilidad de los negocios. Como se pudo evidenciar, en esta comunidad se encuentran negocios que superan los 10 años de antigüedad, es decir, se han logrado sostener a través del tiempo. Sin embargo, su nivel de empleabilidad no supera los tres trabajadores; y teniendo en cuenta que la categoría de microempresa según el número de trabajadores puede ser hasta 10, estas se han quedado en sus niveles mínimos de empleabilidad.

Esta situación muestra a la academia, y en particular a Unicatólica, áreas de acción para esta comunidad, 
enfocadas en apoyar su crecimiento, sostenibilidad y desarrollo, y de esta manera contribuir al progreso de la comuna y la ciudad.

\section{Referencias bibliográficas}

Acuña, G. (2001). EVA. Valor Económico Agregado. Recuperado de https://www.gestiopolis.com/eva-valor-economico-agregadol

Blank, L. y Tarquin, A. (2000). Ingeniería económica. McGraw-Hill. Bogotá.

Carrillo de Rojas, G. (2006). Análisis y Administración Financiera. Panamericana. Bogotá.

Chunga, J., González, M. F. y Márquez, R. H. (2017). Responsabilidad social universitaria: factor de apoyo a la competitividad de las microempresas. Emprendimiento y productividad empresarial. Manuscrito presentado para su publicación.

Mortalidad en empresas Colombianas. (2014). Dinero. Recuperado el 10 de Julio de 2017, de http://wwww. dinero.com/empresas/articulo/mortalidad-empresas-colombia/200984
García, O. L. (2009). Administración financiera fundamentos y aplicaciones. Prensa Moderna Impresores S.A. Cali.

Gitman, L. (2007). Principios de Administración Financiera. Pearson. México.

Hernández, R. H., Fernández - Collado, C., y Lucio, P. B. (2006). Metodología de la Investigación. McGraw-Hill. Ciudad de México.

Jiménez, J. L., Pérez, C. y de la Torre, A. (2008). Dirección Financiera de la Empresa (Teoría y práctica). Ediciones Pirámide. Madrid.

Márquez, R. H. y Chunga, J. (2016). Panorama económico de las empresas de la comuna 18 de la ciudad de Cali. Revista Libre Empresa. 13, 1, 143-159. Recuperado de http://dx.doi.org/10.18041/libemp.2016.013n1.25106

Ramírez, D. N. (2008). Contabilidad Administrativa. McGraw-Hill. México.

Sinisterra, G. y Polanco, L. E. (2007). Contabilidad Administrativa. Ecoe Ediciones. Bogotá.

Valencia, W. (2011). Indicador de Rentabilidad de Proyectos: el Valor Actual Neto (VAN) o el Valor Económico Agregado (EVA). Industrial Data. 14, 1. Recuperado de: http://www.redalyc.org/pdf/816/81622582003.pdf 